Vietnam Journal of Mechanics, NCST of Vietnam Vol. 23, 2001, No 4 (193 - 204)

\title{
NUMERICAL SIMULATION ON MORPHOLOGICAL PROCESS FOR THUAN AN COASTAL AREA
}

\author{
Dang HuU Chung \\ Institute of Mechanics 264 Doi Can, Hanoi, Vietnam
}

\begin{abstract}
The 2DH model is developed and applied to evaluate sediment transport and bed level change in the coastal zone in central Vietnam. The model took the influences of waves and wind into account. Three different options for the flows with or without wind and two wave regimes are calculated. The computed results for flows are calibrated on the base of data measured in Thuan An station in April 1999. The final results from sediment transport model showed that the near shore area from Thuan An to Tu Hien are strongly affected by sediment transport process and the natural flow could change the morphological bed for very long time.
\end{abstract}

\section{Introduction}

Vietnam is a country with the coast length of more than $3200 \mathrm{~km}$ and usually affected by erratic changes of the weather. Hence, the study on the natural mobility law is really necessary. Owing to the features on bathymetry and shoreline, under the action of current and wave a great quantity of sediment appears in the estuaries and coastal areas. A part of it will settle onto the sea bed and the other will be carried away by current and assymetric waves. Many complicated physical processes occur at this stage between suspended sediment and sea bed. The experimental results by Dang Huu C. and Grasmeijer; Grasmeijer, B.T., Dang Huu C., Van Rijn L.C. showed that transport rate due to wave is a considerable part in the total transport rate. Especially, in the case of a storm this is the most important factor for erosion and deposition. Moreover, owing to the action of current and waves the bedload transport also takes a significant part and it is evaluated by mathematical formulae. Sediment transport will affect kinematic regime of flows and it could cause serious and long lasting problems to the economical life of people, such as the floods that happened in 1998 and 1999 in central Vietnam from Thuan An to Tu Hien estuaries. This area with the coast of $43 \mathrm{~km}$ length was damaged seriously and some more estuaries were opened. The environment was changed and many people had to move to other places for residence. Furthermore, the absorption of chemical toxicants and dirty substances in the mixture will pollut the environment and marine ecology system. This paper presents the results on evaluation and prediction for the ability of sediment transport and morphological bed on the basis of the developed software. At the same time, these results are also considered as a scientific base to propose technical solutions to contribute a part into the protection of Vietnam coast 
in the future.

\section{Mathematical basis for the process of morphological bed}

\subsection{Flow model}

The mathematical equations describing the tidal flow are 2DH Saint-Venant equations, in which the eddy diffusion and wind induced stress components are taken into account,

$$
\begin{aligned}
\frac{\partial z}{\partial t}+\frac{\partial(u d)}{\partial x}+\frac{\partial(v d)}{\partial y} & =0 \\
\frac{\partial u}{\partial x}+u \frac{\partial u}{\partial x}+\nu \frac{\partial u}{\partial y} & =-g \frac{\partial z}{\partial x}+\Omega \nu+D\left(\frac{\partial^{2} u}{\partial x^{2}}+\frac{\partial^{2} u}{\partial y^{2}}\right)-g u \frac{\sqrt{u^{2}+v^{2}}}{C^{2} d}+\frac{\tau_{u x}}{\rho d} \\
\frac{\partial v}{\partial t}+u \frac{\partial v}{\partial x}+\nu \frac{\partial v}{\partial y} & =-g \frac{\partial z}{\partial y}-\Omega u+D\left(\frac{\partial^{2} v}{\partial x^{2}}+\frac{\partial^{2} v}{\partial y^{2}}\right)-g v \frac{\sqrt{u^{2}+v^{2}}}{C^{2} d}+\frac{\tau_{w y}}{\rho d}
\end{aligned}
$$

where $x, y$ are Cartesian coordinates along and perpendicular to the shore, respectively, the positive $y$ is directed offshore; $u, v$ - velocity components in $x$ and $y ; z$ water level on chart datum; $g$ - acceleration due to grativity; $C$ - Chezy coefficient; $d$ - water depth; $\Omega$ - Coriolis coefficient; $D$ - eddy viscosity; $t$ - time; $\tau_{w x}, \tau_{w y}$ - wind stresses in $x$ and $y$, respectively and $\rho$ - water density.

\subsection{Sediment transport model}

The sediment transport model includes suspended sediment and bedload transport with the consideration of the exchange between suspension and the bed through the source-sink term, The suspended sediment transport is described by the diffusion equation:

$$
\frac{\partial(d c)}{\partial t}+\frac{\partial(u d c)}{\partial x}+\frac{\partial(v d c)}{\partial y}=\frac{\partial}{\partial x}\left(d E_{x} \frac{\partial c}{\partial x}\right)+\frac{\partial}{\partial y}\left(d E_{y} \frac{\partial c}{\partial y}\right)+S
$$

in which $c$ is mass concentration of suspended sediment; $E_{x}, E_{y}$ - diffusion coefficients in $x$ and $y$, respectively; $S$ - source-sink term determined by the following formula

$$
S=\beta w_{s}\left(c-c_{s}\right)
$$

where $\beta$ is a coefficient; $w_{s}$ - settling velocity of particle; $c_{s}$ - saturated concentration. The values of these parameters are given. Besides, the boundary conditions for suspended sediment concentration are also required.

So far the instrument to measure bedload transport near bed is not available. Therefore, an experimental formula based on instantaneous velocity is used to estimate the bed load transport. There are many formulae for the bedload transport, 
however, the one was proposed by Van Rijn(WL- delft hydraulics, 1998) is used in more general, namely

$$
\frac{q_{b}}{\sqrt{(s-1) g D_{50}^{3}}}=m\left({\overline{\left|\theta^{\prime}\right|-\theta_{c r}}}^{n} \operatorname{sign}\left(\theta^{\prime}\right)\right.
$$

in which $q_{b}$ is the instantaneous transport rate during the wave cycle $\left(\mathrm{m}^{3} / \mathrm{m} / \mathrm{s}\right), s$ - relative density of sediment, $g$ - acceleration due to gravity $\left(\mathrm{m} / \mathrm{s}^{2}\right), D_{50}$ - median grain size of sediment (m), $m, n$ - coefficients, $\theta^{\prime}$ - instantaneous dimensionless bed shear stress and $\theta_{c r}^{\prime}$ - critical dimensionless bed shear stress known as the Shields parameter.

The total sediment transport rate is defined as the sum of suspended sediment and bedload transports:

$$
\begin{gathered}
q_{t t x}=q_{s x}+q_{b x} \\
q_{t t y}=q_{s y}+q_{b y} \\
q_{s x}=\int_{z_{a}}^{h} u(x, y, z, t) c d z ; \quad q_{s y}=\int_{z_{a}}^{h} v(x, y, z, t) c d z ;
\end{gathered}
$$

in which $z_{a}$ is a reference level; $q_{t t x}, q_{t t y}$ - the total transport rates in $x$ and $y$, respectively.

\subsection{The equation governing morphological bed}

The process describing the bed level change with the exchange between suspended and bedload sediment taken into account is as follows

$$
\frac{\partial z_{b}}{\partial t}-\frac{1}{1-p}\left(\frac{\partial q_{t t x}}{\partial x}+\frac{\partial q_{t t y}}{\partial y}\right)=S,
$$

where $p$ is the porisity, $z_{b}$ - bed level with respect to horizontal datum and positive direction is downward

3. Bathymetry and features of the coastal area from Thuan An to Tu Hien

The coastal area under consideration is divided into $228 \times 172$ cells with regular mesh of grid sizes $500 \mathrm{~m}$ (see Fig. 1). The bathymetry data is given from the map with the ratio of $1 / 50000$ and is interpolated on the base of the inverse square distance method. The computed area is $120 \mathrm{~km}$ long and expanded to $80 \mathrm{~km}$ far from the shore so that it can avoid the influence of the boundary on the computed results. The contours of bed level show that the lowest bed level of the area is about $100 \mathrm{~m}$ deep. The contours are distributed regularly and thickly in the area near 
shore. It means that the bed slope in this area is quite large, while the bed slope is small in the area far from the shore and this is one of the reasons why sediment transport ability in near shore area is more significant in comparison with the other areas as knew from the computed results.

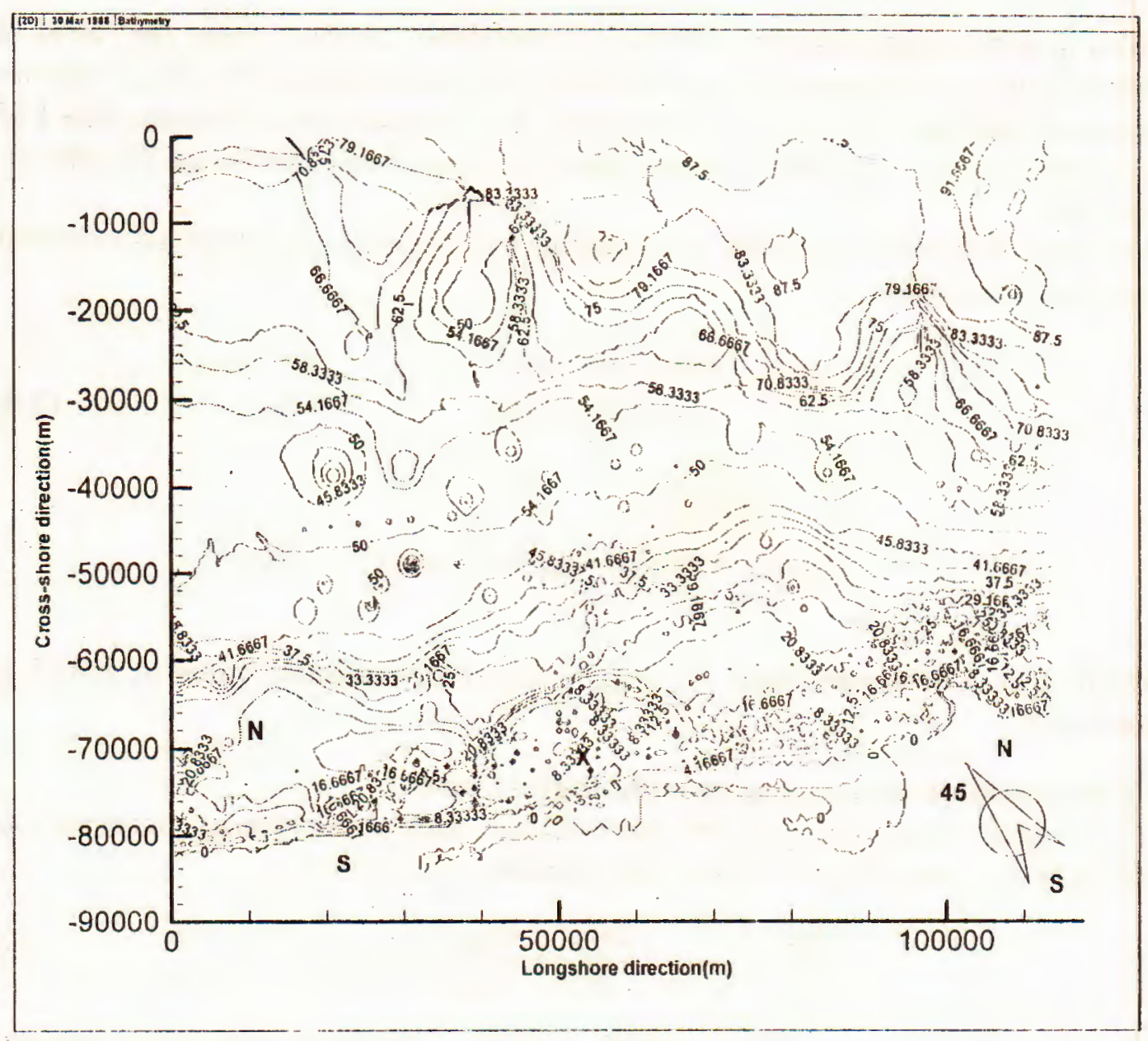

Fig. 1. The bathymetry of the coastal area from Thuan An to Tu Hien

\section{Evaluations of tidal flow field}

The finite difference method based on ADI scheme (D.H.Chung and Bill Roberts) with staggered grid were used for Saint-Venant equations (2.1)-(2.3). The flow model has been calibrated by using the measured data at Thuan An station in April 1999. The comparison between computation and measurement is presented in Fig. 2 and showed quite good suitability. After calibartion for some necessary parameters, the computation is implemented for three different typical options: no wind, southwest wind $(10 \mathrm{~m} / \mathrm{s})$ and north-east wind $(14 \mathrm{~m} / \mathrm{s})$ on the base of boundary condition data of September 2000 from another model. The computed results are presented 
in the Fig. 3 for the cases mentioned above. It consists of water levels, velocity intensities and flow velocity directions over 400 hours corresponding to the three cases of consideration at the position " $x$ " as shown in Fig. 1. The contours of water level and velocity field at $t=400$ hours are presented in Fig. 4 for three different cases: no wind (first line), south west wind (second line) and north east wind(last line).

The Table 1 presents the computed results at this position for the three different options to recognise the kinematic influence of wind on the tidal flow.

Table 1. Influence of wind on tidal flows

\begin{tabular}{|c|c|c|c|c|c|c|c|c|}
\hline \multirow[b]{2}{*}{$\begin{array}{c}\text { Water } \\
\text { level } \\
\text { (m) }\end{array}$} & \multicolumn{2}{|l|}{ No wind } & \multicolumn{3}{|c|}{ South West wind $10 \mathrm{~m} / \mathrm{s}$} & \multicolumn{3}{|c|}{ North East wind $14 \mathrm{~m} / \mathrm{s}$} \\
\hline & $\begin{array}{c}\text { Velocity } \\
(\mathrm{m} / \mathrm{s})\end{array}$ & $\begin{array}{c}\text { Flow } \\
\text { direction } \\
\text { (degree) }\end{array}$ & $\begin{array}{c}\text { Water } \\
\text { level } \\
(\mathrm{m})\end{array}$ & $\begin{array}{l}\text { Velocity } \\
(\mathrm{m} / \mathrm{s})\end{array}$ & $\begin{array}{c}\text { Flow } \\
\text { direction } \\
\text { (degree) }\end{array}$ & $\begin{array}{c}\text { Water } \\
\text { level } \\
(\mathrm{m})\end{array}$ & $\begin{array}{c}\text { Velocity } \\
(\mathrm{m} / \mathrm{s})\end{array}$ & $\begin{array}{c}\text { Flow } \\
\text { direction } \\
\text { (degree) }\end{array}$ \\
\hline $4.10 \mathrm{E}-01$ & $2.39 \mathrm{E}-01$ & $2.63 E+02$ & $4.10 \mathrm{E}-01$ & $2.24 \mathrm{E}-01$ & $2.63 \mathrm{E}+02$ & $4.10 \mathrm{E}-01$ & $2.63 \mathrm{E}-01$ & $2.63 \mathrm{E}+02$ \\
\hline $5.23 \mathrm{E}-01$ & $2.73 \mathrm{E}-01$ & $2.60 \mathrm{E}+02$ & $5.24 \mathrm{E}-01$ & $2.61 \mathrm{E}-01$ & $2.60 \mathrm{E}+02$ & $5.23 \mathrm{E}-01$ & $2.92 \mathrm{E}-01$ & $2.61 \mathrm{E}+02$ \\
\hline $6.06 \mathrm{E}-01$ & $2.84 \mathrm{E}-01$ & $2.64 \mathrm{E}+02$ & $6.07 \mathrm{E}-01$ & $2.75 \mathrm{E}-01$ & $2.64 \mathrm{E}+02$ & $6.06 \mathrm{E}-01$ & $3.01 \mathrm{E}-01$ & $2.64 \mathrm{E}+02$ \\
\hline $6.88 \mathrm{E}-01$ & $2.62 \mathrm{E}-01$ & $2.65 \mathrm{E}+02$ & $6.89 \mathrm{E}-01$ & $2.54 \mathrm{E}-01$ & $2.65 \mathrm{E}+02$ & $6: 87 \mathrm{E}-01$ & $2.75 \mathrm{E}-01$ & $2.65 \mathrm{E}+02$ \\
\hline $7.08 \mathrm{E}-01$ & $2.25 \mathrm{E}-01$ & $2.67 \mathrm{E}+02$ & $7.08 \mathrm{E}-01$ & $2.18 \mathrm{E}-01$ & $2.67 \mathrm{E}+02$ & 7.07E-01 & 2.37E-01 & $2.66 \mathrm{E}+02$ \\
\hline $6.76 \mathrm{E}-01$ & $1.66 \mathrm{E}-01$ & $2.77 \mathrm{E}+02$ & $6.77 \mathrm{E}-01$ & $1.60 \mathrm{E}-01$ & $2.77 \mathrm{E}+02$ & $6.75 E-01$ & $1.78 \mathrm{E}-01$ & $2.76 \mathrm{E}+02$ \\
\hline $6.16 \mathrm{E}-01$ & $8.82 \mathrm{E}-02$ & $2.90 \mathrm{E}+02$ & $6.16 \mathrm{E}-01$ & $8.20 \mathrm{E}-02$ & $2.92 \mathrm{E}+02$ & $6.15 \mathrm{E}-01$ & $1.01 \mathrm{E}-01$ & $2.86 \mathrm{E}+02$ \\
\hline $5.50 \mathrm{E}-01$ & $3.79 \mathrm{E}-02$ & $6.29 \mathrm{E}+00$ & $5.50 E-01$ & 4.03E-02 & $1.88 \mathrm{E}+01$ & $5.49 \mathrm{E}-01$ & $3.67 \mathrm{E}-02$ & $3.38 \mathrm{E}+02$ \\
\hline $4.63 \mathrm{E}-01$ & $1.16 \mathrm{E}-01$ & $6.74 \mathrm{E}+01$ & $4.64 \mathrm{E}-01$ & $1.26 \mathrm{E}-01$ & $6.91 \mathrm{E}+01$ & 4.62E-01 & $9.47 \mathrm{E}-02$ & $6.46 \mathrm{E}+01$ \\
\hline $3.91 \mathrm{E}-01$ & $2.00 \mathrm{E}-01$ & $7.85 \mathrm{E}+01$ & $3.92 \mathrm{E}-01$ & $2.10 \mathrm{E}-01$ & $7.92 \mathrm{E}+01$ & $\$ .90 \mathrm{E}-01$ & $1.78 \mathrm{E}-01$ & $7.81 \mathrm{E}+01$ \\
\hline $3.44 \mathrm{E}-01$ & $2.44 \mathrm{E}-01$ & $8.34 \mathrm{E}+01$ & $3.45 \mathrm{E}-01$ & $2.53 \mathrm{E}-01$ & $8.42 E+01$ & \$.43E-01 & $2.23 \mathrm{E}-01$ & $8.32 \mathrm{E}+01$ \\
\hline $3.19 \mathrm{E}-01$ & $2.71 \mathrm{E}-01$ & $8.68 \mathrm{E}+01$ & $3.19 \mathrm{E}-01$ & $2.79 \mathrm{E}-01$ & $8.77 \mathrm{E}+01$ & $18 \mathrm{E}-01$ & $2.51 \mathrm{E}-01$ & $8.70 \mathrm{E}+01$ \\
\hline $3.45 \mathrm{E}-01$ & $2.78 \mathrm{E}-01$ & $9.06 \mathrm{E}+01$ & $3.45 \mathrm{E}-01$ & $2.86 \mathrm{E}-01$ & $9.12 \mathrm{E}+01$ & $\$ .44 \mathrm{E}-01$ & $2.61 E-01$ & $9.14 \mathrm{E}+01$ \\
\hline $4.07 \mathrm{E}-01$ & $2.73 \mathrm{E}-01$ & $9.54 \mathrm{E}+01$ & $4.08 \mathrm{E}-01$ & $2.80 \mathrm{E}-01$ & $9.55 \mathrm{E}+01$ & $4.07 \mathrm{E}-01$ & $2.58 \mathrm{E}-01$ & $9.64 \mathrm{E}+01$ \\
\hline
\end{tabular}

From the computation the differences on water levels and velocity intensities are evaluated as follows

$$
\begin{aligned}
\max _{t \leq 400}\left\{\left|z_{0}-z_{10}\right|\right\} & \approx 0.002 \mathrm{~m} \\
\max _{t \leq 400}\left\{v_{0}-v_{10}\right\} & \approx 0.02 \mathrm{~ms}^{-1}
\end{aligned}
$$

$$
\begin{aligned}
& \max _{t \leq 400}\left\{z_{0}-z_{14}\right\} \approx 0.004 m \\
& \max _{t \leq 400}\left\{v_{0}-v_{14}\right\} \approx 0.04 m s^{-1}
\end{aligned}
$$

in which $z_{0}, v_{0}$ is water level and velocity correspondin to the flow of no wind at the position under consideration, respectively. 


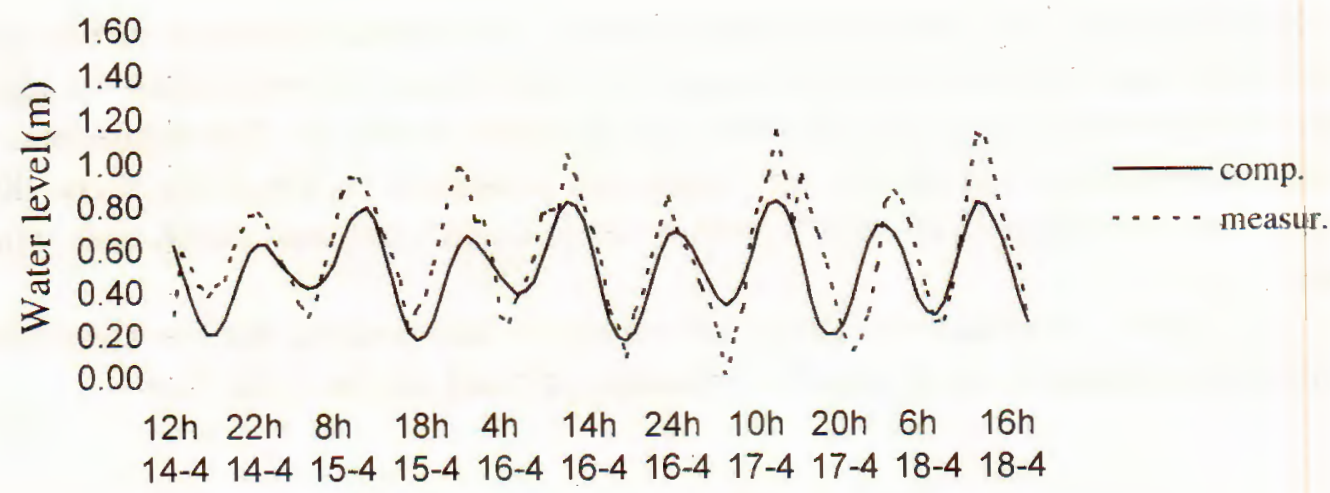

Time (hours)
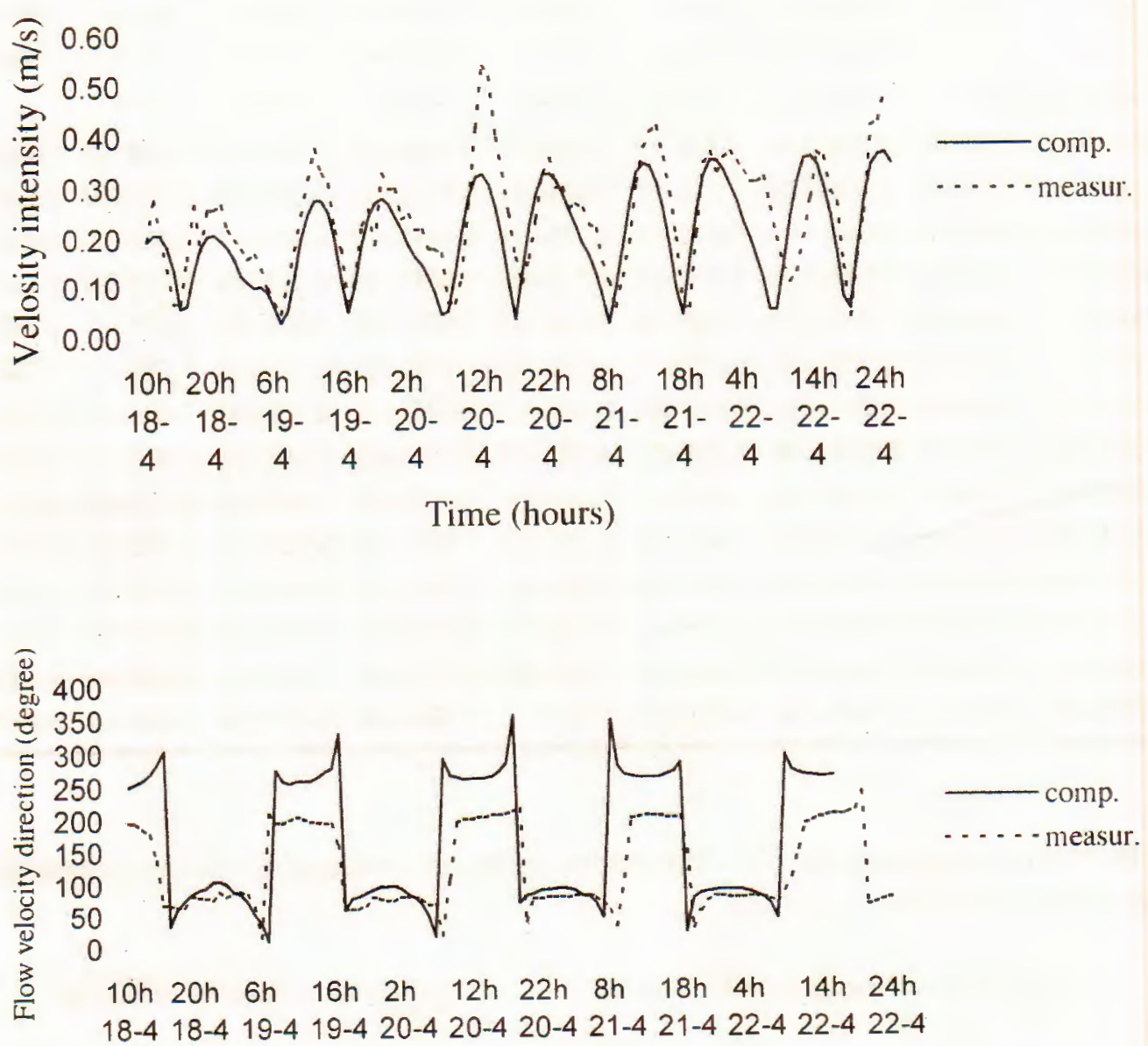

Time (hours)

Fig. 2. Comparison between computation and measurementt at Thuan An station in Appri 1999 

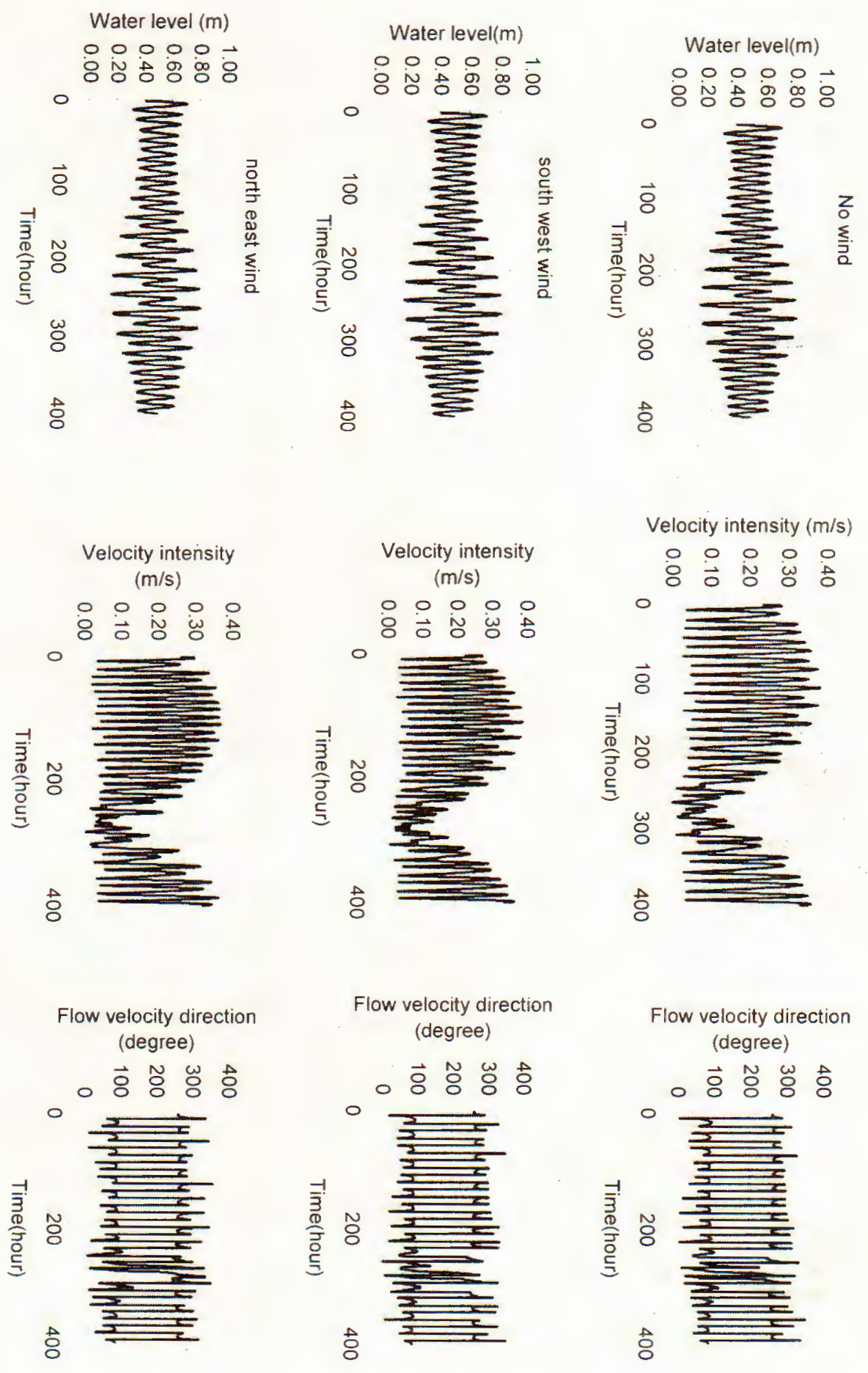

Fig. 3. Computations for flow model for 3 different cases No wind, South-west and north-east winds 

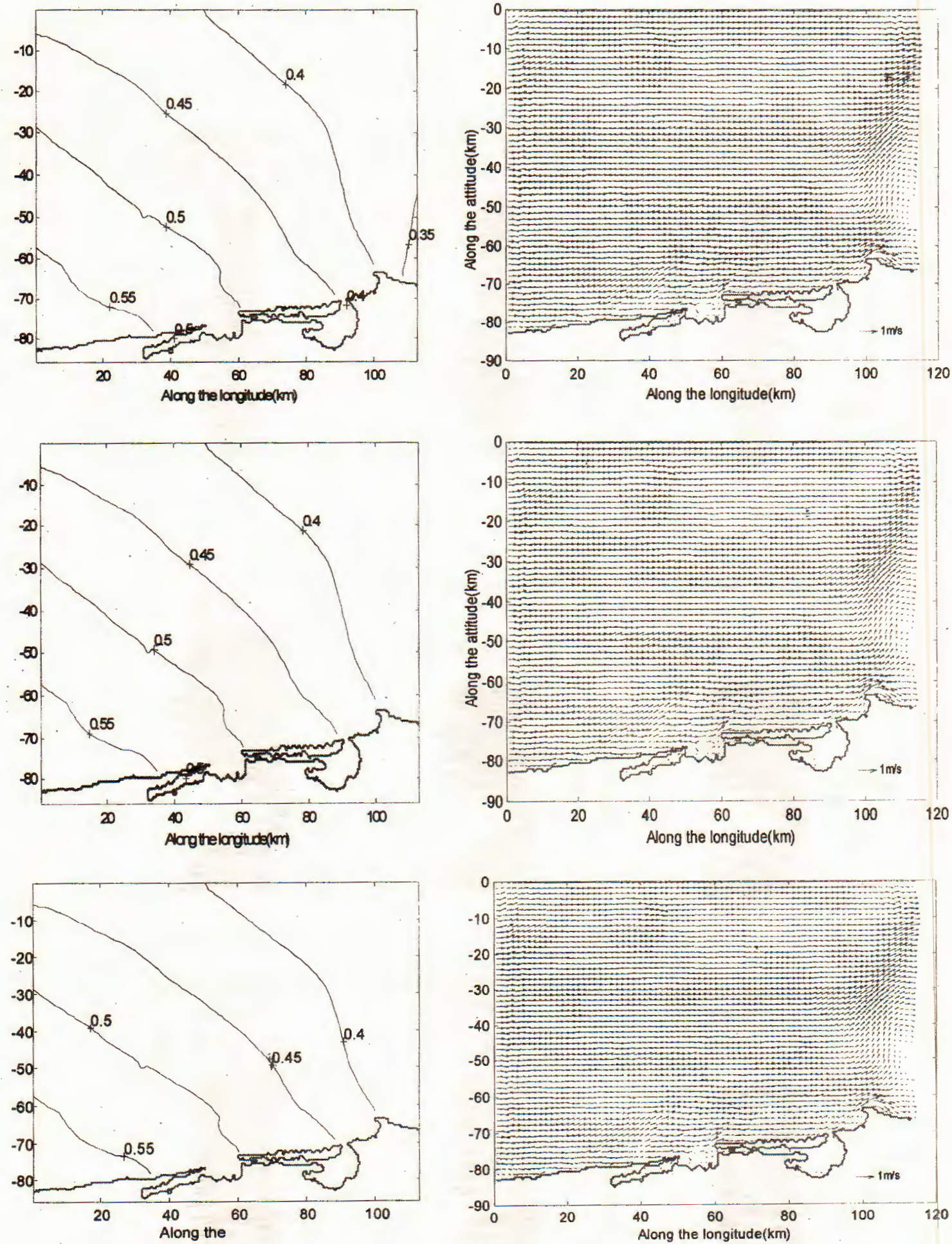

Fig. 4. Contours of water level and velocity field at $t=400$ hours corresponding to 3 case: no wind, south-west and north east winds 
In regards to the flow direction, the big differences only occur for very short time. In general, under considered conditions, the wind affects the kinematic factors of flow, especially intensity of velocity and flow direction. However, the practice experience shows that the action of wind only influences on the surface of flow and at the deeper positions under water the impact is negligible.

\section{Evaluation of sediment transport rate and bed level change}

Sediment transport and morphological process are evaluated in the different conditions for the flow as mentioned above together with the different wave regimes. The equation describing the bed level change is solved with finite difference method with second order Lax-Wendroff scheme, the most popular method for this equation because of its approximation and stability.

Two different wave regimes were used here (see Table 2)

Table 2. Wave parameters

\begin{tabular}{ccccc}
\hline Wave & Wave period & $\begin{array}{c}\text { Onshore } \\
\text { amplitude }\end{array}$ & $\begin{array}{c}\text { Offshore } \\
\text { amplitude } \\
U_{\text {on }}(\mathrm{m} / \mathrm{s})\end{array}$ & $\begin{array}{c}\text { Wave direction } \\
\text { to latitude } \\
\text { off }\end{array}$ \\
\hline$W_{1}$ & $-\mathrm{m} / \mathrm{s})$ & $\alpha$ (dgree) \\
$W_{2}$ & - & - & - & - \\
\hline
\end{tabular}

Fig. 5 are the typical computed results at $t=400$ hours corresponding to the quite large values of flow velocity intensities as presented in Fig. 3 . The Fig. 6 presents the general evaluation of the total sediment transport rates for 400 hours at the position " $x$ ". From these results the following comments can be given:

- Sediment transport rate strongly depends on intensities of flow and wave, so it becomes nearly zero when water level reaches maximum or minimum values, such as at $t=300$ hours corresponding to different cases in Fig. 6. Therefore the morphological process is also uncontinuous.

- Although sediment transport rate occurs everywhere in the area of consideration, however the intensity is only concentrates along the near shore of the coast. Consequently, bed level change only happens in near shore area from Thuan An to Tu Hien, especially in Hoa Duan.

- Bed change level is about $\pm 10 \mathrm{~mm}$ over 400 hours as presented in Fig. 5 in the condition of wind and wave changing not very strongly. This is a short term prediction, in which sudden change of weather is the main factor affects the sediment transport rate and morphological process.

- As the bed level change only occurs along the near shore area, consequently the ability of sediment transport at a typical position should be considered in more 
detail. That is the position " $x$ " shown in Fig. 1. Although the assumed conditions for waves and wind are not quite large, but they can express the action of these factors on sediment transport rate and bed level change. Fig. 6 presents sediment tranisport rates at different time points. Sediment transport rate is equal to zero at $t=300$ hours corresponding to the time when the velocity intensity is very small. It also shows that the transport rates in the case of wind are larger than the transport rate in the case of no wind. and the ratio depends on time and the wind direction.

- In the case of no wind for waves $W_{1}$ and $W_{2}$, the natural flow in normal condition also causes sediment transport and morphological change as shown in Fig.5 (left and right first figures). In general, the erosion and deposition are local and alternative events. However, it can be seen that when the difference of orbital velocity amplitudes is large (such as, wave $W_{2}$ ) then the erosion ability is dominant.

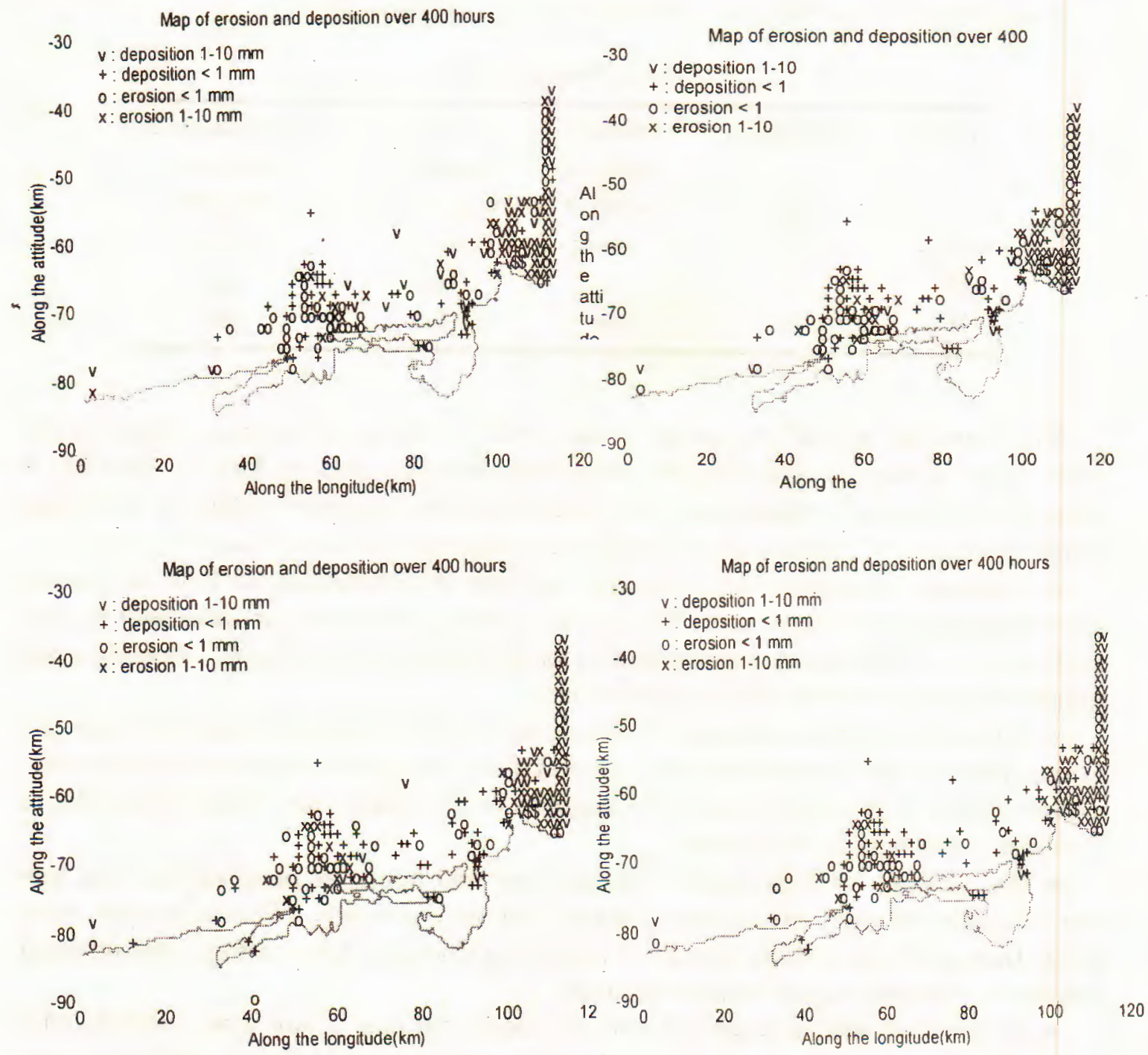




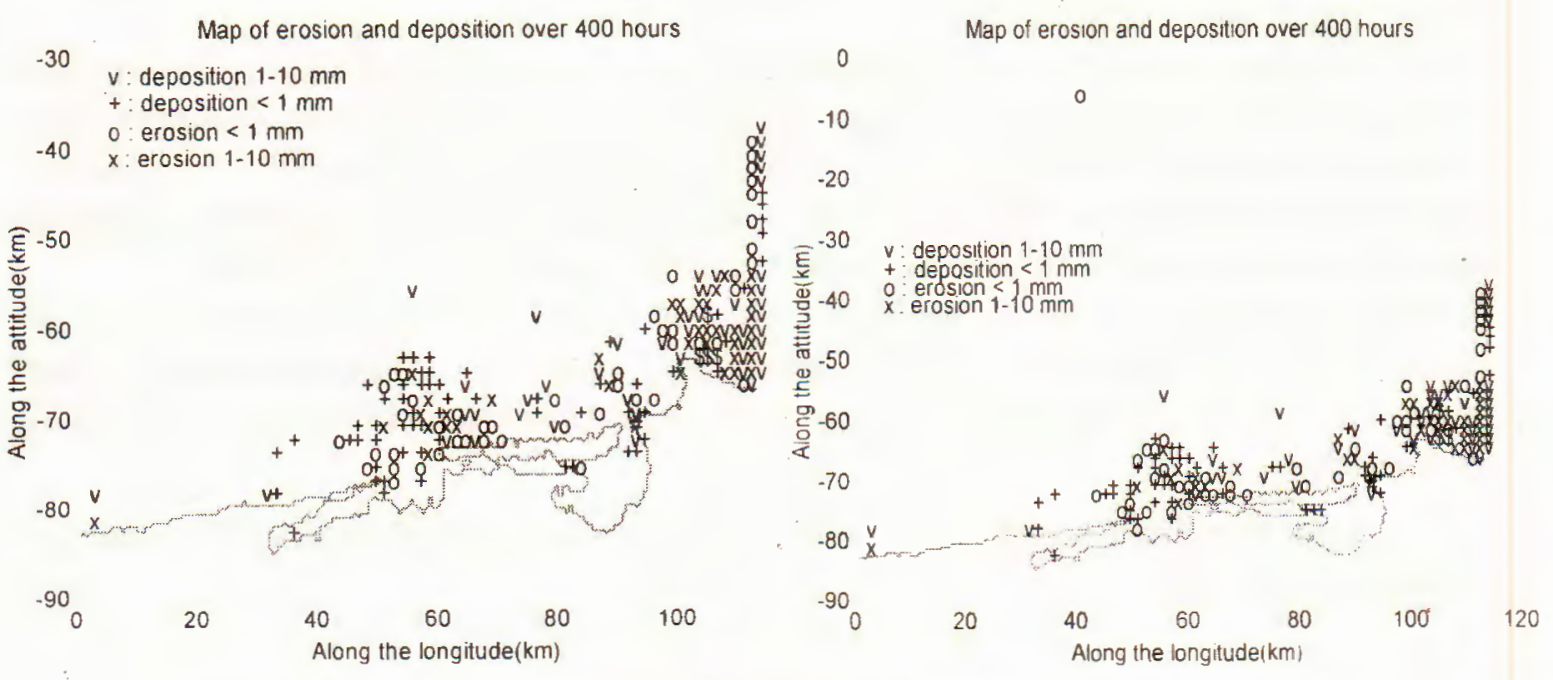

Fig. 5. Position of erossion and deposition for 3 cases with 2 different waves Left : wave W1, Right : wave W2

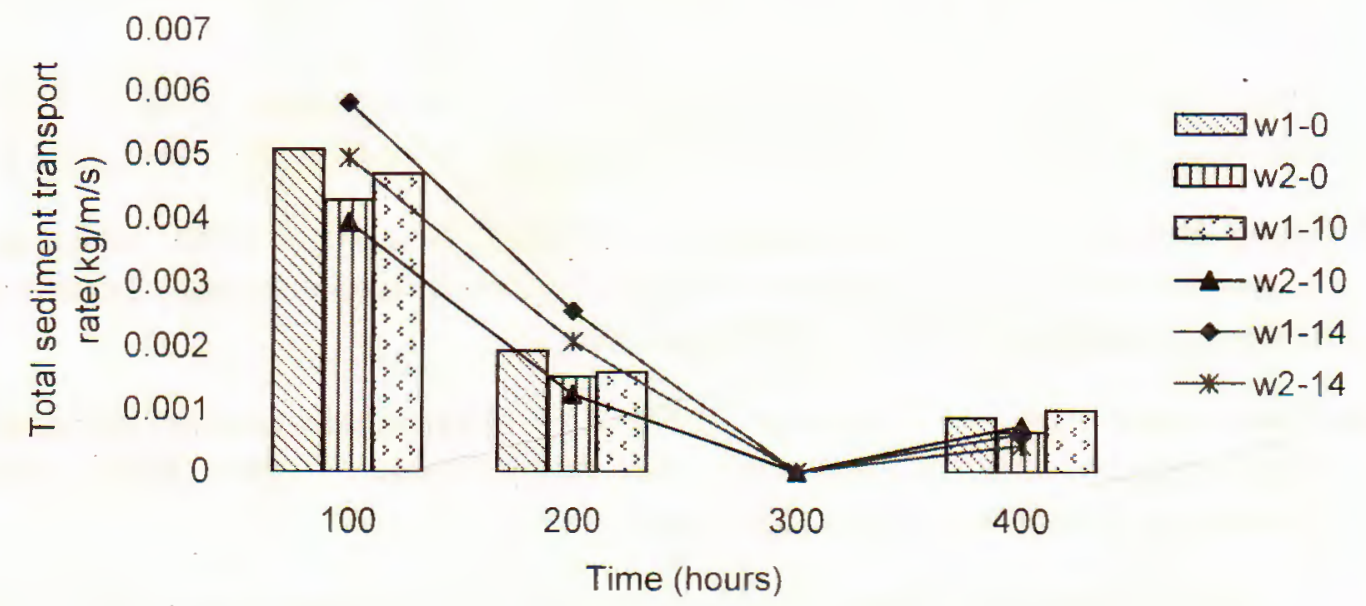

Fig. 6. Total sediment transport rates versus time at the position $\times$

\section{Discussion and conclusions}

- In the coastal zone under consideration, the depth of the sea bed gradually and regularly change in the area far from the shore in the north east with the maximum depth of $100 \mathrm{~m}$. In the near shore area in the south west the depth changes regularly and very quickly, it shows that the bed slope is large along the shore from Hoa Duan to Tu Hien. This is also a reason why sediment transport rate is quite large in this area.

- The flow velocities for three cases are small. Moreover the difference of water level is also quite small (about $0.3 \mathrm{~m}$ ), therefore the sediment particles in normal 
condition of nature are unable to be carried further. Consequently, the sediment transport is only a local event.

- The coastal zone in the north west over Hoa Duan is affected clearly by sediment transport. The evaluation of average sediment quantity shows that this area often suffers deposition. Although it is not much, but the flow in the normal condition has the ability to cause the natural deposition. This is a part to explain the reason why the estuaries were filled with sediment after opening due to a flood.

- However, the above comments could be true in the cases without a harsh weather and the wind field is only steady and constant. Further evaluation and prediction require more data on current, wave and sediment that are not available in Vietnam.

This publication is completed with financial support from the Council for Natural Sciences of Vietnam.

\section{REFERENCES}

1. Dang Huu Chung. Experimental results on sand transport under waves in largescale wave flume, J. of Mechanics, Vol. 22, No.3, pp. 149-166.

2. Dang Huu Chung. 1DV model for suspended sand transport under waves in the surf zone with a ripple regime, J. of Mechanics, Vol.22 (2000), No.2, pp.71-86

3. Dang Huu Chung, B.T. Grasmeijer and Leo C Van Rijn, 1999. Wave-related suspended sand transport under irregular waves in ripple regime, Coastal Engineering Conference, Sydney 2000, pp. 2836-2849.

4. Dang Huu Chung and Grasmeijer, 1999. Analysis of sand transport under regular and irregular waves in large-scale wave flume, Report R99-05, IMAU, Utrecht University, The Netherlands (85 pages)

5. 5. B.T.Grasmeijer, Dang Huu Chung and Leo C. Van Rijn, 1999. Depthintegrated sand transport in the surf zone, Proc. 4th Int. Sym. On Coastal Eng. and Science of Coastal Sediment Processes, New York, June 21-23, 1999, Vol.1, pp.325- 340

6. Dang Huu Chung and Bill Roberts, 1997. Mathematical modelling of siltation on intertidal mudflat in the Severn estuary, Proc. of International Conference on Fluid Engineering, Tokyo, Japan, 13-16 July, 1997, Vol.III, pp.1713-1718

Received June 25, 2001

(xem tiểp trang 256) 